\title{
Digital Tools as a Means to Foster Inclusive, Data-informed Urban Planning
}

\author{
Stéphanie Hasler ${ }^{1, *}$, Jérôme Chenal ${ }^{1}$, Marc Soutter ${ }^{2}$ \\ ${ }^{1}$ Urban and Regional Planning Community (CEAT), Swiss Federal Institute of Technology (EPFL), Lausanne, 1015, Switzerland \\ ${ }^{2}$ Laboratory of Geographic Information System (LASIG), Swiss Federal Institute of Technology (EPFL), Lausanne, 1015, Switzerland
}

Copyright $\odot 2017$ by authors, all rights reserved. Authors agree that this article remains permanently open access under the terms of the Creative Commons Attribution License 4.0 International License

\begin{abstract}
Rapid urbanization, climate change, resource depletion, the desire for more sustainable development and widespread use of the Internet and mobile phones are major challenges for urban planning. While the smart city model is seen as a means to cope with these challenges, it is often reduced to an amalgam of technologies. Citizens are usually seldom included in the planning process, though the knowledge they produce and can share on how they use and live in the city is extremely valuable. Digital technologies create an opportunity to reshape the planning process by improving interactions and information exchanges among urban planners and citizens, which are central in the move towards more sustainable, responsive planning. This research aims to answer the following two questions: (1) how is digital participation changing the role citizens play in urban planning and decision making processes? and, (2) what are the advantages and limitations of involving citizens in these processes through digital tools? This paper explores how digital tools can be harnessed to enhance citizen involvement in the planning process. We will give an overview of how these tools can inform urban planning by providing citizen-centric data to foster more inclusive and responsive planning. This paper identifies both the opportunities - particularly in terms of data production and exchange - and limitations of digital tools.
\end{abstract}

Keywords Digital Participation, Digital Tools, Urban Data, Responsive City, Inclusive Urban Planning

\section{Introduction}

Cities are home to more than half of the World's population and are thus crucial for building a sustainable future. While the smart city model has been put forth as a solution to the sustainable city challenge for almost two decades [1], it has reached its limit. While there is no clear, broadly accepted definition of the smart city concept, all include the massive use of information and communication technology for creating more liveable, efficient, sustainable cities [2-7]. However, smart cities focus mainly on urban management, such as optimizing urban flows, resources and systems such as traffic control $[6,8$ 10]. The city's smart citizens, though deemed central, often play a peripheral role $[7,9]$. Yet, city dwellers play a key role in producing and sharing useful data on how they live and use the city. Many researchers note that smart city projects lack social consideration and point to the importance of shifting the focus from a technology-oriented vision to a people-based vision $[7,11$, 12]. Although technological innovations have improved everyday life for urban dwellers by helping them make better-informed decisions, the data produced through these innovations are rarely used to inform urban planning [8, 13].

Public participation in urban planning is not new; in fact, extensive literature on this subject already exists [14-16]. For instance, the public was first involved in a federal program, the Urban Renewal Program, in the United States in 1954 [17]. As Rowe and Frewer [18, p. 512] describe this concept, "public participation may be defined at a general level as the practice of consulting and involving members of the public in the agenda-setting, decision-making, and policy-forming activities of organizations or institutions responsible for policy development." In this study, participation is applied to urban planning and has a range of implications, from informing the public to involving citizen as stakeholders. This is also referred to as participatory planning. Since the 1960's, a whole gamut of tools and techniques for participatory planning have been developed, including referenda, public hearings, public surveys, conferences, public meetings, public advisory committees and focus groups [18]. A plethora of critiques and guides have been published subsequently. In 1969, Sherry Arnstein [19] published an often-cited article wherein she deplores the fact that participation is often not a veritable redistribution of power, but rather is used as a way to argue that all parties 
have been considered. And yet, the benefits of citizen participation in urban planning have been firmly established. Evans-Cowley and Hollander [20] note that participation allows for better acceptance of urban planning policies and projects [11]. Zubizarreta et al. argue that citizens are the main protagonists of cities and that, "without this active role of the citizen, real smart cities cannot exist" [9, p.2]. Participatory planning is crucial to the development of sustainable cities as it ensures planning based on the practices and needs of inhabitants. Furthermore, stricter adherence to sustainable actions and policies helps foster in sustainable projects [21]. Urban planning is a complex process bringing together many actors, including citizens. It is therefore essential to find ways to encourage and support interactions [22]. Nevertheless, numerous challenges hinder conventional participatory processes, among them the need for participants to be in a particular place at a given time, lack of representativeness, limitations in the number of attendees, the duration and costs of such processes, and the lack of motivation among citizens $[17,20]$. The forms and content of participatory processes are under still debate, as there is no universally accepted method [17].

With the widespread use of smartphones, the Internet and social media, people can now easily express their opinions. Participatory planning has, as such, become even more relevant as these wide-spread sentiments cannot be ignored. Digital technologies are effectively a new way of coping with the shortcomings of participatory planning processes. Many studies are focusing on the opportunities ICT-based participation offer [15, 20, 23-28]. Digital participation includes any participatory process that uses digital tools, such as PPGIS (public participation geographic information systems) [27], visualization tools (e.g. CAD, virtual reality) [24], mobile applications [23] or crowdsourcing and collaboration platforms [14, 29]. All agree that digital technologies show great potential for positive use in participatory planning. Yet, how citizens and urban planners will produce and use urban data remains to be defined.

Related works until now have merely identified and described specific tools, but do not provide an overview of the latter or their capacity to produce data. Furthermore, the literature tends to focus on the tools themselves, and not on the outcomes and benefits for urban planning. It is important to understand the implications of these tools in participatory planning in order to take advantage of their benefits and enhance current planning practices. The aim of this study is to provide an overview of the potential of digital tools using citizen-centric data to inform urban planning, and to identify their advantages and shortcomings. We begin by presenting a general framework in which we classify digital participation tools. In the second section we assess the data production capacity of these methods and current data usage through an extensive literature review and report analysis. Finally, we identify the advantages and limitations of digital participation tools in the urban planning process.

\section{Research Methods}

This research attempts to determine how digital tools can be used in participatory processes to generate and exchange data for future planning. To this end, we built a catalogue of the different digital tools used for public participation worldwide. These tools include web-based platforms, mobile phone or tablet applications, as well as other types of technology-based devices used to collect data from citizens, such as sensors. The sample of case studies was formed based on examples cited in the literature, Google requests, web portals such as Planetizen [30] and Engaging Cities [31], and our findings from semi-directed interviews with experts and practitioners in the field of participatory urban planning. Some examples of tools include processes involving social media platforms such as Twitter, Foursquare and Flick, serious games, various forms of online surveys (Figure 1), crowdsourcing and collaboration platforms. Most of the platforms and mobile applications selected focus on urban planning, but the scope of this investigation has been broadened to include thematically-related projects such as governance and urban management tools, which can also produce useful insight for urban planning. All the examples in our sample can be accessed online. However, several are introduced and used during face-to-face meetings via computers or tablets. The tools in our sample come from a variety of cities in different countries, including England, France, Helsinki, Indonesia, The Netherlands, Norway, Portugal, Russia, Singapore, Spain, Sweden, Switzerland and The United States. This list is not exhaustive. The BlockbyBlock project [32], for instance, has been used in numerous cities in Africa, Latin America, Asia and Europe. The tools selected were developed by companies and start-ups, academics, NGOs (e.g. UN-Habitat), public organizations and agencies from both the public and private sectors. The sample includes tools that are or have been used in participatory and planning processes, pilot projects, and academic projects. Several case studies (6) that have not actually tested in a city are also included in the sample.

72 examples were listed in the initial sample. Similar tools were then grouped together. Since this research mainly focuses on the production and collection of data, we then excluded case studies whose only purpose was to inform the public. This resulted in a total of 48 entries. These entries were then summarized in a table to allow for comparison. Each of the 48 case studies was analyzed based on the type, source and format of the data generated, the type of interactions, the degree of participant involvement, the actors involved, and data use and outcomes. This analysis grid, along with a description of the tool, formed the table's columns. The analysis focuses on two aspects relative to data, namely its production and 
its utilization. Information on the tools in the sample was gathered through the literature review, report analysis and tool testing. Interviews with developers, academics and practitioners who implemented or promoted the sample tools allowed for a better understanding of how they were implemented and used, which data were collected, as well as the outcomes, benefits and shortcomings. The data collected on the case studies were then classified in order to identify different typologies according to three parameters, which are described below: the degree of involvement, the type of data produced and how data were used. From this overview we extracted the potential advantages and shortcomings of digital tools for participatory planning. This paper attempts to answer two research questions: (1) how does digital participation change the citizen's role in urban planning and decision making processes? (2) what are the advantages and limitations of involving citizens in these processes through digital tools?

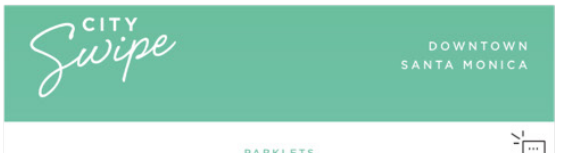

Would you give up a couple parking spaces for this?

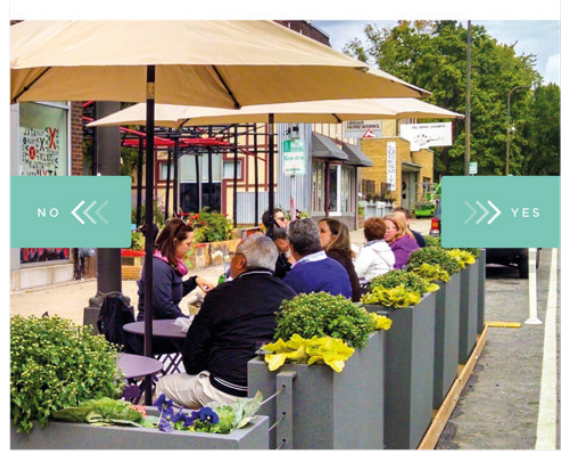

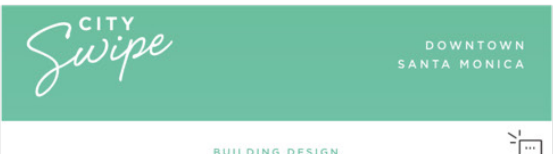

Which building do you prefer?

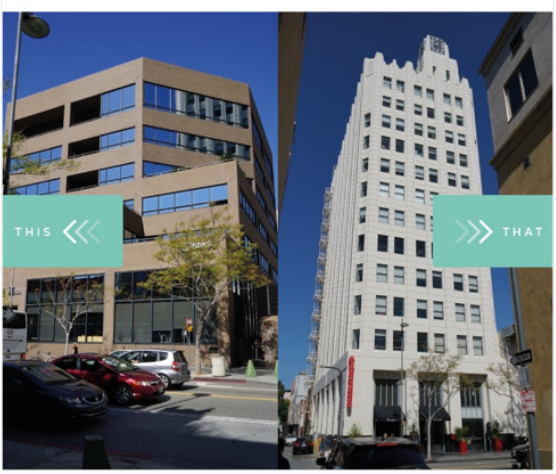

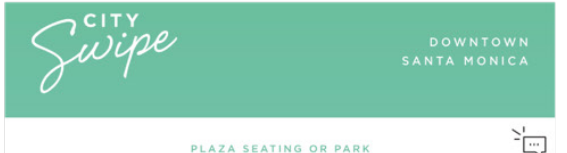

Which would you prefer to have Downtown?

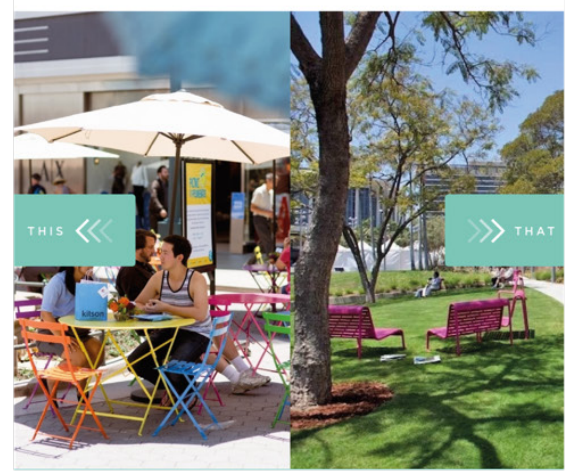

Figure 1. Screenshots of the City Swipe online survey application (source: http://www.dtsmcityswipe.com)

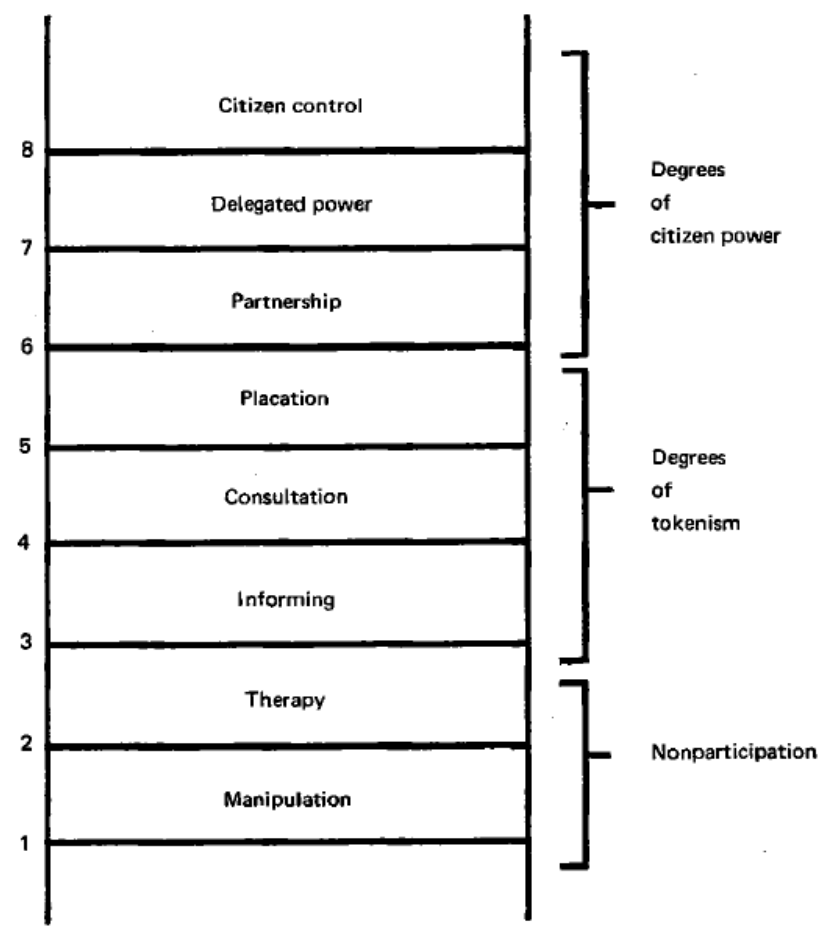

Figure 2. Arnstein's Ladder [19] 


\section{Analysis \& Results}

\subsection{Classification framework}

Opportunities for participation are not uniform and can be categorized into different types. To understand the various possibilities, we developed a conceptual framework to categorize our sample into distinct typologies of involvement. In 1969, Arnstein [19] was the first to propose a ladder to classify participatory processes according to the citizen's power to determine or change the final outcome. This eight-step ladder (Figure 2) was reused and adapted several times (see for example [33, 34]). However, given the changes that have taken place in recent decades, these classifications are now outdated and do not accommodate digital tools. Yet, such a ladder is essential for acknowledging the different forms of digital participation and establishing the role and involvement of citizens in participatory planning processes. The existing classifications do not adequately reflect the diversity of elements brought to light by this research, as digital aspects are not taken into account. Rather, a new scale that is adapted to recent changes in the field is needed. Based on previous works $[19,33,34]$, we therefore propose a new ladder (Figure 3) that includes digital participation methods [35]. This new scale allowed us to categorize our sample of digital case studies and understand variations. Moreover, contrary to most of the previous classifications, our classification framework does not focus on citizens' role in decision making, which is difficult to measure accurately [18]. Instead, it focuses on the contributor's degree of involvement through the interactions between participants and urban authorities. This means the higher the degree of involvement, the more numerous the exchanges. At the two lowest rungs of the ladder top-down and bottom-up information - the interactions are one-way. At the consultation level, participants answer urban officials' questions, for example, through online surveys. Contribution refers to platforms or mobile applications that allow citizens to share their opinions on specific projects or topics. Participants are not limited by closed questions and can exchange with the urban officials. At the collaboration level, citizens can share their ideas and propositions and freely interact. For example, participants can vote or comment on the ideas and opinions of other contributors. The highest level, Empowerment, was omitted from the study, as no classifiable example could be found at this stage. In addition, although some digital tools used for informing the public were included in the initial sample, the first rung of our ladder - top-down information - was not relevant in the following analysis and therefore excluded from the investigation. However, informed participants are crucial for effective participation.

The main difference between the new ladder and existing classifications is the bottom-up information level, which includes information produced by inhabitants that is not specifically requested by the urban officials. This level is intrinsically linked to digital participation. In addition, we included both passive and active data production modes in our sample [13]. Passive data production refers to data that people produce inactively, i.e. through mobile apps using positioning information, public transport cards or social media. People are often unaware of the information they share. Passive data is a rich source of information about the social fabric of cities and is essential to understanding usage patterns and real-time urban dynamics. Active data production, on the contrary, includes all information people willingly share on dedicated platforms.

Compared to Arnstein's ladder, our classification framework grouped the first three rungs of Arnstein's ladder - manipulation, therapy and informing - in the top-down information rung. As mentioned above, informing the public is not relevant to this study as it does not enable citizens to produce data. Thus we associated it with what Arnstein considers non-participation. Moreover, the proposed ladder describes the degree of interaction between the stakeholders and not the participant's impact on decision-making. Steps 4 through 6 of Arnstein's ladder - consultation, placation and partnership - are similar to levels 3 through 5 of our framework - consultation, contribution and collaboration. The two highest rungs of Arnstein's ladder correspond to empowerment.

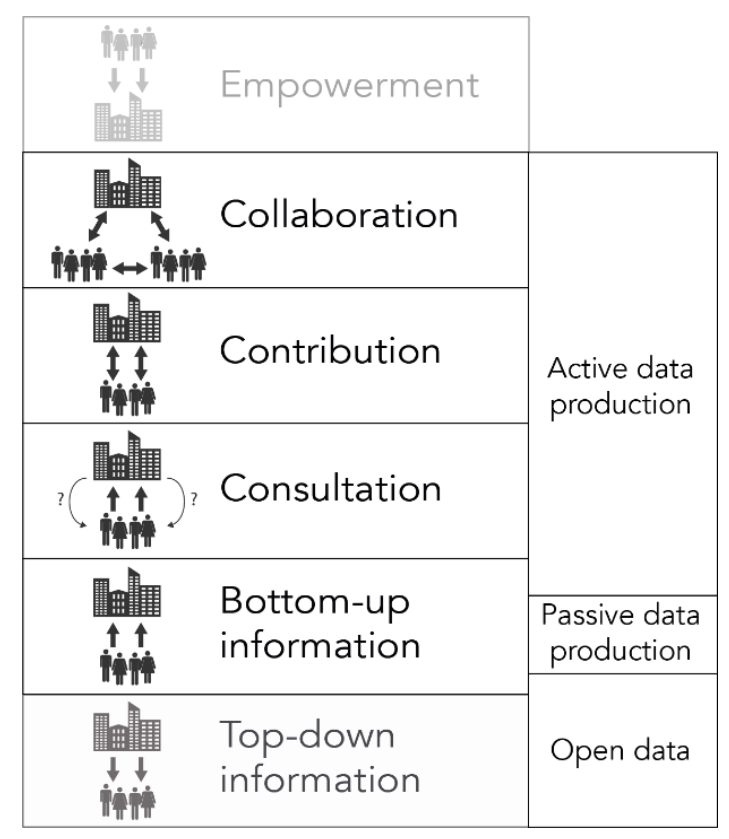

Figure 3. New ladder proposal (source: author)

\subsection{Types of Urban Data}

Digital participation tools can inform urban planning by producing various types of data. To categorize the collected information, the planning process is divided into three general phases. The first phase, diagnostic, refers to the examination of the existing situation so as to identify challenges and shortages. This stage serves to set the goals 
of the planning process. The following knowledge can be collected through digital participation:

- Data can provide information about use patterns. For example, it can offer insights on behaviours, travels or the location of activities of urban dwellers.

- An inventory of existing features or challenges can be produced through data collection, such as collaborative mapping.

- Citizens can share information regarding their needs, e.g. cycling lanes or green spaces.

- Data can provide information about how people perceive their environment. Feelings such as happiness or safety can be mapped through data collection.

In the second phase, development, the project, plan, vision or policies are developed, and different scenarios can be tested. Data can be used in this phase to produce information about:

- Predictions, meaning information that helps in identifying parameters that impact how people use or behave in space. In other words, it produces information that can determine how layout or constructive elements influence the way people use the planned space. This can assist planners in achieving the goals.

- Preferences, meaning data that provides information about what people prefer, e.g. building typology, types of public space such as parks or plazas, etc.

- Ideas, meaning suggestions shared by the public, which can be directly used or adapted to fit into the design.

The final phase is decision-making, wherein the final project or vision to be implemented is chosen. Digital tools can allow citizens participate by:

- Providing an overview of proposals made by city authorities or planning agencies. For example, inhabitants can share their opinions on a project, vision or intention. They can also assess the proposals of other participants.

Actual planning processes are, in fact, more complex, thus making it difficult to sort information into strict categories. Nevertheless, this classification helps us to understand the range of possibilities available for informing urban planning at each stage. We clearly observe that city dwellers can potentially produce a variety of data that can be used to inform the early stages of planning. Hence the importance of involving citizens from the beginning of the planning process.

\subsection{Use of data}

The impact of digital participatory tools in urban planning is difficult to measure [18]. Therefore, we propose to identify whether the collected data were used to inform planning, regardless of the actual influence they might have had on the outcome of the planning process. This study shows that the use and outcomes of data from digital participation practices are often unclear; it is not always possible to identify how the produced data are employed in the urban planning process. Nevertheless, we can identify three situations:

- Data were used: the results of data analysis were used by planners to inform urban planning. The results report is generally included in the planning documents.

- Data were not used: it was acknowledged that data were not used to inform urban planning.

- Data were partially used: data were not directly used to inform planning, but were used as a basis for on-site participatory meetings and discussions or to validate the outcome of non-digital participatory processes. We also classified cases when a similar method or platform was used several times but the results were not necessarily seen as informing planning in this category.

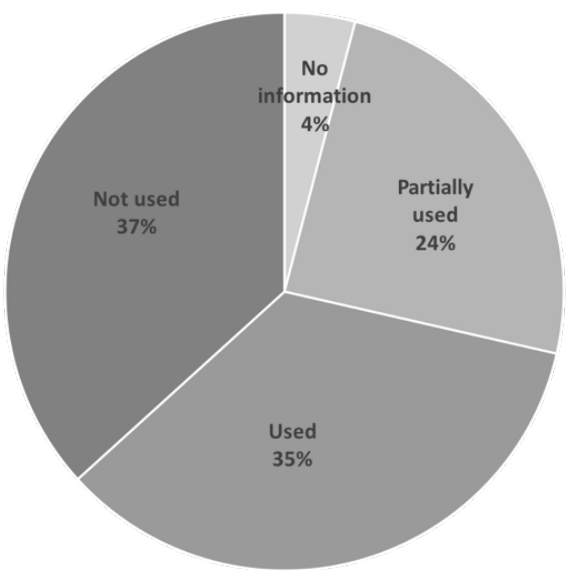

Figure 4. Distribution of the examples regarding use of data

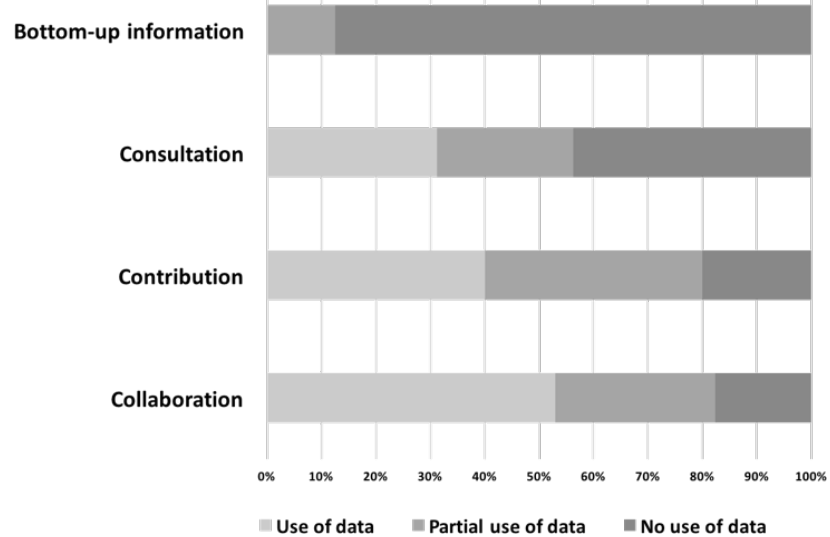

Figure 5. Comparison between the use of information and the level of participation

Figure 4 shows that the generated data were used only in 
approximately one third of the cases. In the other cases it was either not used at all (37\%), was partially used (24\%), or it was impossible to determine whether it was used or not $(4 \%)$. A comparison with the degree of involvement (Figure 5) shows that data were not used in more than $85 \%$ of the cases at the bottom-up information level. In contrast, data were clearly used to inform planning approximately half of the time at the contribution and collaboration level. These results indicate that the more people are involved in the process, the more the outcome informs urban planning. This is mainly due to the fact that there are more interactions and exchange with higher degrees of involvement. It is therefore easier to include input in the planning process. However, the fact that several case studies from the bottom-up information level were only included in experimental projects, and not in an actual planning process, can be misleading.

Interviews and reports on the case studies allowed us to identify several explanations for the lack of connection to actual planning processes and lack of data usage.

- This study highlighted the fact that the actor who initiates the project can have an important impact on the non-use of data. For example, the actual implementation of outcomes strongly depends on political motives (such as elections, if, for example, it originates from representatives), which can easily put an end to an ongoing project. Some of the examples used by private organizations were not actually used for planning due to the lack of exchange between the organization and agencies in charge of urban development. When academics initiated the project, the data were not effectively used to inform urban planning in approximately half of the cases. However, these projects are usually well-documented. This is part of effort to document and understand the causes of poor data usage, but only by focusing on how the tool is used.

- $\quad$ The lack of flexibility of current urban planning policies and processes, often linked to a rigid legal framework and political unwillingness to change procedures, leads to poor data usage.

- The inadequacy of the strategies applied to meet the needs of planners or citizens results either in irrelevant or useless data or a lack of indicative participation.

- Participatory processes that emerge too late in the planning process generate data that cannot be used.

- Planning agencies often consider such data not sufficiently reliable or believe that digital tools do not generate relevant, indicative results and thus ignore them.

- Too often, participatory processes (with or without digital tools) exist to fulfil legal needs. In this case, the data produced are generally not used to inform planning.

- Outcomes from digital tools are used for the purposes of promotion, to highlight the innovative nature of the city, but are sometimes not actually used to inform planning.

- $\quad$ Finally, lack of skills and resources for processing and analysing the data is another cause of poor data usage.

\subsection{Advantages of digital participation}

Digital participatory platforms and mobile applications "amplify" data production possibilities. This concept is borrowed from E. Eisenstein's work on printing [36] and has been used by D. Boullier [37] to explain how digitalization accentuates a process or phenomenon. This study showed that digital tools increase participation by allowing more people to participate and produce input. It also makes it possible to reach new socio-demographic profiles such as young people and families, and is therefore a way of amplifying unheard voices. Moreover, digital tools provide access to more diverse data in terms of type and format. It also makes it possible to collect data that were inexistent or difficult to gather, like information on perceptions, real time data, opinions or ideas. Such citizen-centric urban data collected using digital methods generate both novel and more accurate insight about the city. For instance, instead of counting the number of cars that pass at a given location and time, we can now see how people are moving around an entire city or region in real time. Furthermore, it is even possible to determine the mode of transport used by analysing mobility data, e.g. from mobile phones, thus producing unprecedented knowledge. 

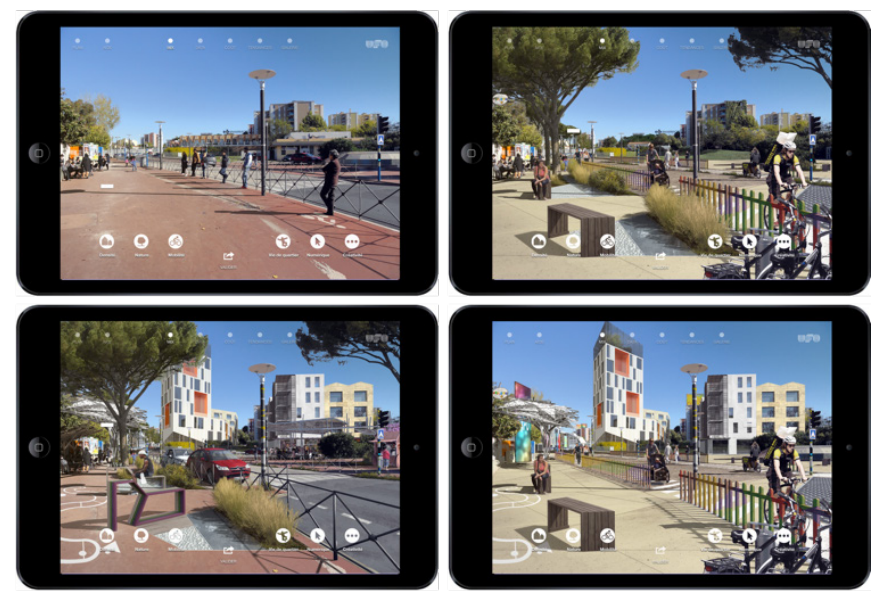

Figure 6. Screenshots from the Unlimited Cities mobile application (source: Unlimited Cities App)

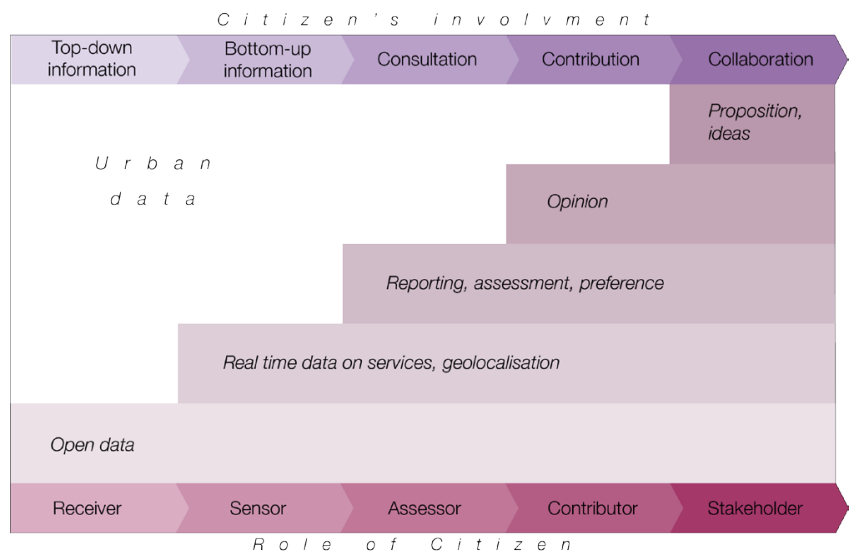

Figure 7. Evolution of the citizen's role with the production of new urban data [35]

Though most digital tools used for participatory urban planning translate real action into digital action, new forms of participation can be identified. These new participatory methods allow participants to be more immersed in the planning process. This is the case for techniques that use augmented and virtual reality, or role-playing video games. For example, the Unlimited Cities mobile application [38] (Figure 6) was inspired by the concept of augmented reality to allow participants to generate a new photo-realistic image of the city by playing with various sliders such as density, nature, mobility, creativity and liveliness. Online participation tools are also changing the role citizens play in the development of their cities. By producing new urban data and being more involved in planning processes, inhabitants go from passive recipients to actors [13,39]. By simply remaining informed through open data by city authorities, city dwellers can become co-planners by submitting propositions and discussing their ideas (Figure 7). Nevertheless, while citizens are increasingly involved in the sharing of urban knowledge, opinions and ideas, the actual impact on urban planning is still difficult to measure. As we mentioned above, this study shows that the use of urban data in planning processes is often uncertain.

\subsection{Limitations of digital participation}

The multiplication and diversity of contributions increase complexity. Inhabitants produce immense quantities of heterogeneous data through digital tools, raising the question of which information should be taken into account and what data are the most relevant. As there is generally no room for debate, it is difficult to prioritize input, particularly given that citizens' opinions can be conflicting. It is also crucial to balance citizens' input with that of experts. Voting or feedback systems can highlight the more popular or controversial issues. Boullier and Lohard [40] propose a way of objectifying subjective data through codification and expert assessment. However, we must still find ways to analyse these data and translate contributions into meaningful knowledge.

There cross-section of the population in participatory urban planning is never representative. This becomes even more complicated with digital practices as there is often no formal identification and online profiles can greatly differ from offline profiles, and thus is a paradigm shift. To cope with this shortcoming, we propose reducing participants to their attributes. People share various features (likes, opinions, ideas, etc.) online. As it is difficult to associate 
these characteristics with a given person, each should be considered individually. In this sense, people act as sensors that collect information on a given question or phenomenon.

Finally, the question of privacy is a crucial aspect of digital participation. Personal data should be protected. City authorities should therefore be transparent about how the collected data are and will be used, and who accesses these data. Furthermore, it is important to enable citizens to participate anonymously to ensure privacy. As such, data anonymization techniques can help to protect participants' privacy.

\section{Discussion}

Studies on digital participation methods focus on specific tools or group of tools (e.g. social media, PPGIS), or rely on a particular context. Moreover, research often addresses the tool itself (i.e. its development and technical features) rather than the outcomes and benefits for urban planning. This results in a lack of insight on how digital participatory tools can be used to inform planning practices. To overcome these weaknesses, we propose a more global approach that involves investigating and assessing the current digital participatory planning toolbox. This research differs from existing work by providing an analysis of digital participation tools regarding the types of knowledge produced, and how these data are or can be used in the urban planning process. This paper provides an overview of possible uses of digital participation to inform planning at each stage of the process by investigating a diverse sample of tools and techniques. We demonstrate that a plethora of tools to fulfil independent aims already exists and can be used at different planning stages and scales. These involve a contrasting range of interactions, from one-way information transmission to dialogue between stakeholders. This shows that multiple participatory tools and methods need to be implemented in planning procedures to promote better-informed, people-based plans and policies. Seltzer and Mahmoudi already highlighted the fact that 'useful citizen involvement will be the result of a multiplicity of techniques and opportunities in a planning process, not a single form or moment in time' [14, p.13]. This paper demonstrates that digital tools for participation produce diversified knowledge at each stage of a planning process. As such, combining different tools and methods is a key driver of evidence-based, citizen-centric planning processes.

The success of participatory planning is rarely assessed, as doing so is a complex task. Rowe and Frewer [18] present a research agenda designed to evaluate the effectiveness of public participation actions. Yet, they admit that effectiveness is hard to define given its multiple dimensions. Consequently, numerous instruments and techniques must be developed to measure the success of public participation. Gordon et al. [17] argue that the success of participatory processes is often measured according to the number of participants. In this paper, we evaluate the outcome of digital participation based on whether the produced data were, in fact, used to inform the urban planning process; in other words, we determine whether urban planners have access to the information produced through participatory procedures despite its lack of influence on decision-making. We assess the effectiveness of digital participation processes by focusing on the availability of information to urban planners. We then determined whether this information was considered during planning (i.e. if data were used) or for other actions (i.e. if data were partially used). This research emphasizes the gap between data production, collection, and actual use of this information in the planning process, as the results of the participatory procedure are often not included in the planning process (i.e. data were not used or were partially used). Moreover, decision-makers do generally not participate in planning processes. Hence, data are rarely used for decision-making, even though they were used to inform planning. This highlights a second gap between urban planning and decision making and, notably, the need to redefine the administrative framework and decisionmaking process in order to fully harness digital participation. Digital participation tools' potential for improving planning processes has been posited. However, new issues emerge from the data produced and collected through digital participation interfaces. This paper identified a major gap in the use of data for decision-making that makes it impossible to take advantage of these tools. Digital planning requires different tools and knowledge in order to be implemented effectively and achieve the expected result. To this end, the role of the urban planner should be redefined from expert, top-down decision-maker to facilitator for synthesizing pieces of relevant input. Furthermore, citizens, as local experts, should be considered as sources of relevant data.

Even with the multiplication of mobile applications and platforms, many researchers [23, 24] highlight the fact that digital tools are often only used for case studies and are seldom employed in actual planning processes. Hanzl [24] argues that most of the examples described in literature are experimental and only verify available technical possibilities. However, this research shows that this is changing, as many examples of the analysed sample were included in a planning process, even if the data were not always used to inform the process. Moreover, several tools were used in different planning processes and in different cities. Our study highlights that a key condition of effective use of digital participation tools is proof of their value and their inclusion in the planning process. In his review of public participation in planning, Lane [16] demonstrated that opportunities for participation are strongly linked to planning practices. Consequently, the choice of tools is 
very important. The right tool can provide valuable input for improving urban planning. Moreover, when the information collected is relevant and used to inform urban planning, citizens derive greater decision-making power. As a result, this paper shows that in order to be valuable to planning, it is essential to know what information is needed and how it will be analysed and used before collecting it.

\section{Conclusion}

Given the number of platforms and mobile applications, there is no doubt that digital planning is extremely promising for data collection. However, the limitations underlined in this research point to the need to rethink the entire planning system, from communication and information exchange between stakeholders to the skills of urban planners. Yet, digital tools should not replace other practices. Instead, they should be regarded as a new layer of knowledge that can be used to inform urban planning at each phase of the process. Hence, combining a multiplicity of methods and tools is indispensable to achieve evidence-informed, people-centric urban planning. However, there is still a considerable gap between data production/ collection and effective use of data that must be filled in order to promote actual changes and promote inclusive, informed planning processes.

This research develops a new conceptual framework for classifying and understanding the potential of digital tools. It also describes data production and collection capacity, and how data are currently used in planning processes. As a result, it provides a three-dimensional overview based on interactions, produced knowledge and actual outcome that allows us to answer the research questions. This study begins by explaining how digital tools allow citizens to play a new role in shaping their environment. It then highlights how digital participation can empower citizens and enhance urban planning processes. Furthermore, it shows that digital tools create new planning perspectives by considering urban processes based on user-generated data. Finally, this study was successful in determining some of the limitations that prevent the smart city model from moving towards more data-informed, inclusive planning and hence a responsive city. Further research on the question is needed to understand how these tools can be included in existing planning processes, and how the data produced and collected can efficiently become part of the process. It is also crucial to identify the keys for changing current practices so as to fully integrate these new forms of participation.

\section{REFERENCES}

[1] V. Albino, U. Berardi, and R. M. Dangelico, Smart Cities:
Definitions, Dimensions, Performance, and Initiatives, Journal of Urban Technology, Vol. 22, No. 1, 1-19, 2015.

[2] R. P. Dameri and C. Rosenthal-Sabroux, Eds., Smart city, New York, Springer, 2014.

[3] R. Kitchin, The real-time city? Big data and smart urbanism, GeoJournal, Vol. 79, No. 1, 1-14, 2013.

[4] R. Kitchin, Making sense of smart cities: addressing present shortcomings, Journal of Regions, Economy and Society, Cambridge, 2014.

[5] P. Lombardi and A. Vanolo, Smart City as a Mobile Technology: Critical Perspectives on Urban Development Policies, in M. P. Rodríguez-Bolívar, Ed.,Transforming City Governments for Successful Smart Cities, Springer International Publishing, 147-161, 2015.

[6] A. Picon, Smart cities: a spatialised intelligence. Wiley, Chichester West Sussex, 2015.

[7] A. Vanolo, Smartmentality: The Smart City as Disciplinary Strategy, Urban Stud, Vol. 51, No. 5, 883-898, 2014.

[8] M. Batty, Big data, smart cities and city planning, Dialogues in Human Geography, Vol. 3, No. 3, 274-279, 2013.

[9] T. Nam and T. A. Pardo, Smart City as Urban Innovation: Focusing on Management, Policy, and Context, Proceedings of the 5th International Conference on Theory and Practice of Electronic Governance, New York, USA, 185-194, 2011.

[10] A. M. Townsend, Smart cities: big data, civic hackers, and the quest for a new utopia, WWNorton, New York, 2013.

[11] P. Neirotti, A. De Marco, A. C. Cagliano, G. Mangano, and F. Scorrano, Current trends in Smart City initiatives: Some stylised facts, Cities, Vol. 38, 25-36, 2014.

[12] I. Zubizarreta, A. Seravalli, and S. Arrizabalaga, Smart city concept: What it is and what it should be, Journal of Urban Planning and Development, Vol. 142, No. 1, 2016.

[13] P. V. Thakuriah, N. Tilahun, and M. Zellner, Big Data and Urban Informatics: Innovations and Challenges to Urban Planning and Knowledge Discovery, Proceedings NSF Workshop on Big Data and Urban Informatics, 4-32, 2015.

[14] E. Seltzer and D. Mahmoudi, Citizen Participation, Open Innovation, and Crowdsourcing: Challenges and Opportunities for Planning, Journal of Planning Literature, Vol. 28, No.1, 1-16, 2012.

[15] R. Kleinhans, M. V. Ham, and J. Evans-Cowley, Using Social Media and Mobile Technologies to Foster Engagement and Self-Organization in Participatory Urban Planning and Neighbourhood Governance, Planning Practice \& Research, Vol. 30, No. 3, 237-247, 2015.

[16] M. B. Lane, Public Participation in Planning: an intellectual history, Australian Geographer, Vol. 36, No. 3, 283-299, 2005.

[17]E. Gordon, S. Schirra, and J. Hollander, Immersive Planning: A Conceptual Model for Designing Public Participation with New Technologies, Environment and Planning B: Planning and Design, Vol. 38, No. 3, 505-519, 2011.

[18] G. Rowe and L. J. Frewer, Evaluating Public-Participation 
Exercises: A Research Agenda, Science, Technology, \& Human Values, Vol. 29, No. 4, 512-556, 2004.

[19] S. R. Arnstein, A Ladder of Citizen Participation, Journal of the American Institute of Planners, Vol. 35, No. 4, 216-224, 1969.

[20] J. Evans-Cowley and J. Hollander, The New Generation of Public Participation: Internet-based Participation Tools, Planning Practice \& Research, Vol. 25, No. 3, 397-408, 2010.

[21] A. Martos, R. Pacheco-Torres, J. Ordóñez, and E. Jadraque-Gago, Towards successful environmental performance of sustainable cities: Intervening sectors. A review, Renewable and Sustainable Energy Reviews, Vol. 57, 479-495, 2016.

[22] A. Kunze, R. Burkhard, S. Gebhardt, and B. Tuncer, Visualization and Decision Support Tools in Urban Planning, in Digital Urban Modeling and Simulation, Springer, Vol. 242, Berlin, 279-298, 2012.

[23] T.-P. Ertiö, Participatory Apps for Urban Planning-Space for Improvement, Planning Practice \& Research, Vol. 30, No. 3, 303-321, 2015.

[24] M. Hanzl, Information technology as a tool for public participation in urban planning: a review of experiments and potentials, Design Studies, Vol. 28, No. 3, 289-307, 2007.

[25] S. Levy, K. Martens, and R. van der Heijden, The Everyone City: How ICT-Based Participation Shapes Urban Form, in Planning Support Systems and Smart Cities, Springer, 313336, 2015.

[26] Z. Khan, D. Ludlow, W. Loibl, and K. Soomro, ICT enabled participatory urban planning and policy development: The UrbanAPI project, Transforming Government: People, Process and Policy, Vol. 8, No. 2, 205-229, 2014.

[27] M. Kahila-Tani, A. Broberg, M. Kyttä, and T. Tyger, Let the Citizens Map-Public Participation GIS as a Planning Support System in the Helsinki Master Plan Process, Planning Practice \& Research, Vol. 31, No. 2, 195-214, 2016.
[28] M. Foth, L. Forlano, C. Satchell, and M. Gibbs, Eds., From social butterfly to engaged citizen: urban informatics, social media, ubiquitous computing, and mobile technology to support citizen engagement, Mass: MIT Press, Cambridge, 2011.

[29] D. C. Brabham, Crowdsourcing the Public Participation Process for Planning Projects, Planning Theory, Vol. 8, No. 3, 242-262, 2009.

[30] Planetizen, Online available from https://www.planetizen.com/.

[31] EngagingCities, Online available from http://www.engagingcities.org.

[32] Block By Block, Projects. Online available from https://blockbyblock.org/projects/.

[33] M. Blanc, Politique de la ville et démocratie locale. La participation : une transaction le plus souvent différée, Les Annales de la recherche urbaine, Vol. 68, No. 1, 99-106, 1995.

[34] IAP2 International Federation, IAP2's Public Participation Spectrum. International Association for Public Participation, 2014.

[35] S. Hasler, J. Chenal, and M. Soutter, Digital tools and citizen participation: Towards sustainable and responsive urban planning, Urban planning and Property Development Conference Proceedings, Singapore, 2017.

[36] Elizabeth L. Eisenstein, La révolution de l'imprimé à l'aube de l'Europe moderne. Editions La Découverte, Paris, 1991.

[37] D. Boullier, Sociologie du numérique. Armand Colin, Paris, 2016.

[38] Unlimited Cities. Online available from http://unlimitedcities.org.

[39] M. Saujot and T. de Feraudy, Urban crowdsourcing: digital technologies for sustainable cities?, Iddri Blog, 2016.

[40] D. Boullier and A. Lohard, Opinion mining et Sentiment analysis : Méthodes et outils., OpenEdition Press, Marseille, 2012. 